\title{
A HUMAN HEMOGLOBIN WITH LOWERED OXYGEN AFFINITY AND IMPAIRED HEME-HEME INTERACTIONS *
}

\author{
By KURT R. REISSMANN, WILLIAM E. RUTH AND TAKEO NOMURA \\ (From the Department of Medicine, University of Kansas Medical Center, Kansas City, Kans., \\ and the Department of Medicine and Research, VA Hospital, \\ Kansas City, Mo.)
}

(Submitted for publication April 19, 1961 ; accepted June 8, 1961)

The reactivity of the iron in the four hemes of the mammalian hemoglobin molecule depends largely on the interactions between the prosthetic groups and the amino acid chains of the globin $(1,2)$. Normal configuration of heme groups in the abnormal human hemoglobins, therefore, does not preclude anomalies of their oxygen affinity which might arise from aberrations in the globin. In most of the more than 20 recognized abnormal human hemoglobins the amino acid abnormality does not affect the oxygen affinity. Amino acid changes which are remote from groups crucial in the globin-heme interaction do not affect oxygenation. Abnormal oxygen affinities have been reported in hemoglobin $\mathrm{H}$ and $\mathrm{M}$. Hemoglobin $\mathrm{H}$ contains only the beta and not the alpha chains of normal hemoglobin and exhibits an oxygen affinity ten times greater than normal but has no Bohr effect (3). Hemoglobin $M$ causes cyanosis apparently due to its inability to combine with oxygen. The pigment may be present in the blood as methemoglobin $\mathrm{M}$ or as its nonoxidized precursor (4).

We have recently encountered a hemoglobin which caused cyanosis due to an abnormally low oxygen affinity. The entire oxyhemoglobin dissociation curve was markedly shifted, but at sufficiently high oxygen tensions the pigment became fully saturated. The oxygen equilibria, spectroscopic and preliminary electrophoretic findings are presented. Since a lowered oxygen affinity of hemoglobin is usually not considered in the differential diagnosis of cyanosis, some reference is made to the methods which lead to its detection.

\section{PROPOSITUS}

The patient, a 14 year old white male of normal growth and superior intelligence, has been cyanotic since birth.

* Supported by a grant from the Kansas Heart Association. Presented in part at the National Meeting of the American Federation for Clinical Research, April 30, 1961, in Atlantic City, N. J.
No clubbing, squatting or shortness of breath has ever occurred, but he has had some episodes of weakness after severe exertion. Pulmonary function tests, including diffusion studies, were within normal limits. Hemoglobin was $13.9 \mathrm{~g}$ per cent; erythrocytes 4.6 million; reticulocytes 1.4 per cent; red cell morphology normal. Examination of the blood for methemoglobin or sulfhemoglobin was negative. Cardiac catherization, including dye injection studies, revealed on three different occasions low arterial and venous oxygen content but no evidence of cardiovascular abnormalities.

The patient is an only child. His grandparents are deceased; his father's hemoglobin is normal. His mother's hemoglobin showed almost quantitatively the same abnormalities as that of the patient. One brother and sister of the mother as well as one male and one female descendent of the brother have normal hemoglobin A.

\section{METHODS}

Arterial and venous blood samples were taken during inhalation of various $\mathrm{O}_{2}-\mathrm{N}_{2}$ mixtures. All gas samples were analyzed in an $\mathrm{E}_{2}$ Beckman oxygen analyzer. The oxygen tension of blood was determined with a ClarkSeveringhaus oxygen electrode (5) (Yellow Springs Instrument Corp.) and the oxygen and carbon dioxide of the blood by the manometric technique of Van Slyke and Neill. Blood $\mathrm{pH}$ was measured at $37^{\circ} \mathrm{C}$ in an anaerobic electrode with a Beckman model $\mathrm{M} \mathrm{pH}$ meter. The determination of the oxygen capacity of the blood under these circumstances required special attention to the following possibilities: 1) the usual equilibration of blood in vitro may not fully saturate the heme pigments in the sample and 2) the spectrophotometric measurements of the hemoglobin concentration may not be valid when dealing with an abnormal pigment with unknown light absorption constants. The total hemoglobin concentration was therefore ascertained by three methods: 1) spectrophotometric hemoglobin iron determination after wet ashing (6) and calculation of the pigment concentration on the basis of hemoglobin iron concentration of 0.335 per cent; 2) gasometric measurement of the oxygen capacity after equilibration of the blood in vitro with oxygen at $20^{\circ} \mathrm{C}(1.34 \mathrm{cc}$ oxygen equivalent to $1 \mathrm{~g}$ hemoglobin); and 3) spectrophotometric measurement of the pigment after its conversion into cyanmethemoglobin, applying a millimolar extinction coefficient of 11.5 at 542 $\mathrm{m} \mu$ (7). Absorption spectra of the undiluted blood after anaerobic lysis with saponin were obtained using a cuvet of $0.0087 \mathrm{~cm}$ thickness (Waters-Conley Corp.) in a Beck- 
man DU spectrophotometer. Ultraviolet spectra were obtained with a Cary recording spectrophotometer. All optical densities were expressed per $1 \mathrm{~cm}$ light path and as the concentration of 1 mmole per $\mathrm{L}$ of the subunit (mol wt 16,700) of hemoglobin. One mmole per L of the subunit corresponds to $1.67 \mathrm{~g}$ per cent hemoglobin ( $\mathrm{mol}$ wt 67,000).

Hemoglobin solutions were prepared at $4^{\circ} \mathrm{C}$. After repeated washings with saline, the cells were lysed with approximately twice their volume of distilled water plus 5 per cent toluene. After centrifugation at $25,000 \mathrm{G}$ for 30 minutes, the decanted clear hemoglobin solution was mixed with buffer of desired $\mathrm{pH}$ and ionic strength. Oxygen equilibria studies were carried out on freshly prepared hemoglobin solutions of approximately $6 \mathrm{~g}$ per cent concentration in $0.15 \mathrm{M}$ phosphate buffer. Samples were equilibrated in a tonometer with $\mathrm{O}_{2}-\mathrm{N}_{2}$ mixtures at $37^{\circ}$ and $28^{\circ} \mathrm{C}$ water-bath temperatures for $20 \mathrm{~min}$ utes. The hemoglobin solution was then transferred anaerobically into the $0.0087 \mathrm{~cm}$ cuvet, and oxyhemoglobin $\left(\mathrm{HbO}_{2}\right)$ and reduced hemoglobin $(\mathrm{Hb})$ fractions were determined spectrophotometrically according to the method of Drabkin (8). The absence of methemoglobin was verified in each sample by preparation of a companion sample with addition of freshly neutralized $\mathrm{KCN}$ and comparison of the two absorption spectra.

Spectrophotometric studies on methemoglobin (MetHb) were made on dilute solutions in phosphate or borate buffer after oxidation of the pigment at $\mathrm{pH} 6.5$ by potassium ferricyanide which was added to the hemoglobin solution in molar ratio of 6 to 1 . The percentage of alkaline and acid methemoglobin at a given $\mathrm{pH}$ was ascertained according to the method of Austin and Drabkin (7). All $\mathrm{pH}$ values were corrected to 0.1 ionic strength. The methemoglobin dissociation was calculated according to the equation $\mathrm{pH}=\mathrm{pK}+\log$ (alkaline MetHb/acid MetHb).

Electrophoretic studies were done on granular or gel starch blocks, cooled with circulating ice water (9). A current of approximately $40 \mathrm{ma}$ at $250 \mathrm{v}$ was applied. Electrophoresis of oxyhemoglobin, carboxyhemoglobin, methemoglobin and cyanmethemoglobin was studied at $\mathrm{pH} 8.6$ (veronal buffer, 0.05 ionic strength) and at 7.4, 7.05 and 6.5 (phosphate buffer, 0.05 ionic strength).

\section{RESULTS}

In vivo oxygen saturation of the blood. While the patient was breathing room air his arterial oxygen tension was normal and ranged between 96 and $104 \mathrm{~mm} \mathrm{Hg}$. The oxygen content of the arterial blood, after subtraction of the oxygen in physical solution, increased by about 35 per cent between room air and 100 per cent oxygen breathing, clearly indicating incomplete saturation of the hemoglobin at a usual arterial oxygen tension of $100 \mathrm{~mm} \mathrm{Hg}$. After equilibration of the blood in vitro at $20^{\circ} \mathrm{C}$ with oxygen, its gasometrically
TABLE I

Total hemoglobin* measured as hemoglobin iron, cyanme! moglobin and oxygen capacity

\begin{tabular}{lccc}
\hline \hline & $\begin{array}{c}\text { Hemoglobin- } \\
\text { iron } \\
\text { Gasometrict } \\
\text { (vol \% O2/1.34) } \\
\left.\times 10^{-3}\right)\end{array}$ & $\begin{array}{c}\text { Cyanmethemo- } \\
\text { globin } \\
\text { (mmoles/L } \\
=11.5 \text { at 542 } \mathrm{m} \mu)\end{array}$ \\
\hline Patient & $13.91 \pm 0.14$ & $14.02 \pm 0.09$ & $13.98 \pm 0.09$ \\
Normal & $14.24 \pm 0.16$ & $14.30 \pm 0.12$ & $14.32 \pm 0.08$
\end{tabular}

* Figures given are given in $\mathrm{g} \%$ as mean \pm standard deviation of three determinations.

† After equilibration of the blood with $100 \% \mathrm{O}_{2}$ at $20^{\circ} \mathrm{C}$.

measured oxygen capacity agreed satisfactorily with its capacity calculated on the basis of the heme iron determination (Table I) indicating that all hemes present had combined with oxygen. An in vivo oxygen saturation curve (Figure 1) was constructed accordingly and demonstrated an enormous shift to the right. There was saturation of 60 per cent in the arterial blood at a normal $\mathrm{P}_{\mathrm{O}_{2}}$ of $100 \mathrm{~mm} \mathrm{Hg}$, and a saturation of 94 per cent during oxygen inhalation. An in vitro dissociation curve of the blood showed essentially the same results.

While the patient was breathing room air the $\mathrm{pH}$ of the arterial blood was 7.38 and its $\mathrm{CO}_{2}$ content 22.2 mmoles per $\mathrm{L}$. The $\mathrm{CO}_{2}$ content of the arterial plasma was 27.3 mmoles per L, indicating a normal distribution of the $\mathrm{CO}_{2}$ between plasma and corpuscles.

Oxygen equilibria of hemoglobin preparations in buffer solutions. Hemoglobin, freed of stromata and lipids, in $0.15 \mathrm{M}$ phosphate buffer solution was equilibrated against known $\mathrm{O}_{2}-\mathrm{N}_{2}$ mixtures

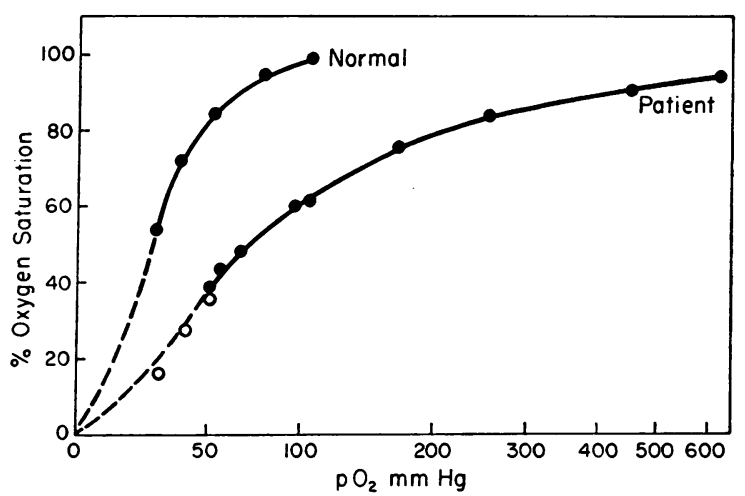

Fig. 1. IN VIVO OXYGEN SATURATION OF ARTERIAL BLOOD DURING INHALATION OF $\mathrm{O}_{2}-\mathrm{N}_{2}$ MiXtures; BLOOD $\mathrm{PH} 7.34$ To 7.39. Open circles are measurements in venous blood. 


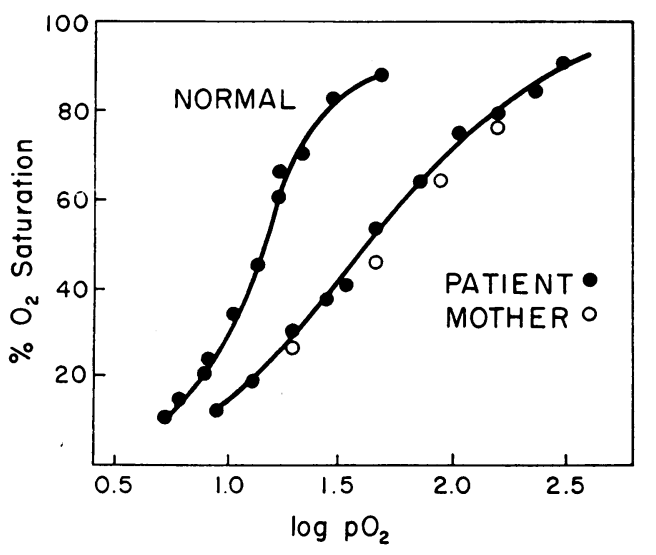

Fig. 2. OXYGEN EQUILIBRIA OF HEMOGLOBIN (APPROXIMATELY $6 \mathrm{G}$ PER CENT) IN $0.15 \mathrm{M}$ PHOSPHATE BUFFER AT $37^{\circ}$ C. $\mathrm{pH}$ : patient, 7.37 ; mother, 7.36 ; normal control, 7.39 .

and the resultant dissociation curves are presented in Figure 2. As observed by others $(10,11)$, the oxygen affinity of freed hemoglobin was considerably greater than that of intact red cells, a phenomenon probably due to differences in $\mathrm{pH}$, $\mathrm{CO}_{2}$ and ionic concentrations in the environment of the hemoglobin molecules. As a dilute hemoglobin solution, normal hemoglobin A required 14 $\mathrm{mm} \mathrm{Hg} \mathrm{P}_{\mathrm{O}_{2}}$ to produce 50 per cent saturation versus $40 \mathrm{~mm} \mathrm{Hg}$ for the patient's hemoglobin. As intact blood, 50 per cent saturation points were at $\mathrm{P}_{\mathrm{O}_{2}}$ of $25 \mathrm{~mm} \mathrm{Hg}$ for the normal control compared with $70 \mathrm{~mm} \mathrm{Hg}$ for the patient. In other words the patient's hemoglobin in buffer solutions as well as in intact cells required oxygen tensions roughly 2.8 times greater than normal for halfsaturation. Four-hour dialysis of the hemoglobin solutions prior to the equilibration did not materially alter the oxygen equilibria. Hemoglobin solutions prepared from blood of the patient's mother showed a dissociation curve almost identical with that of the patient.

The grossly abnormal shape of the patient's dissociation curve in Figure 2 should be noted. The asymmetry of the curve was not caused by the presence of methemoglobin or by partial denaturation of the hemoglobin. Both conditions, which are common causes of asymmetrical curves, were eliminated by spectroscopic examinations.

The steepness of the normal curve in the plot of oxygen saturation versus $\log \mathrm{P}_{\mathrm{O}_{2}}$ (Figure 2 ) is related to heme-heme interactions. A numerical expression of the intensity of these interactions can be obtained from Hill's equation : $\log (y / 100$ $-y)=\log K+n \log \mathrm{P}_{\mathrm{O}_{2}}$ where $y$ is the per cent oxyhemoglobin, $n$ is an expression of the heme interactions ( $n=1=$ no interactions), and $K$ is a measure of the affinity for oxygen. The $n$ value was calculated for the slope in the range of 50 per cent saturation and was 2.6 for normal hemoglobin and 1.1 for the patient's hemoglobin.

The effect of $\mathrm{pH}$ on the oxygen equilibria of the patient's hemoglobin was not different from that on the normal control (Figure 3). These measurements were made at $28^{\circ} \mathrm{C}$ and a comparison with measurements at $37^{\circ} \mathrm{C}$ indicates a somewhat smaller temperature effect on the affinity of the abnormal hemoglobin than on the normal.

Spectroscopy of the native pigments. Spectrophotometric examinations were made with the following objectives: 1) to ascertain the nature of the pigment which remained unoxygenated in the patient's blood in vivo and 2) to obtain ultraviolet absorption spectra with particular attention to signs of possible denaturation of the pigment.

After complete saturation with oxygen in vitro, the blood was quickly hemolyzed and examined in the $0.0087 \mathrm{~cm}$ cuvet. Its absorption spectrum was identical with that of normal oxyhemoglobin (Figure 4). After evacuation at zero oxygen tension, a normal reduced hemoglobin absorption spectrum was found. Arterial and venous blood

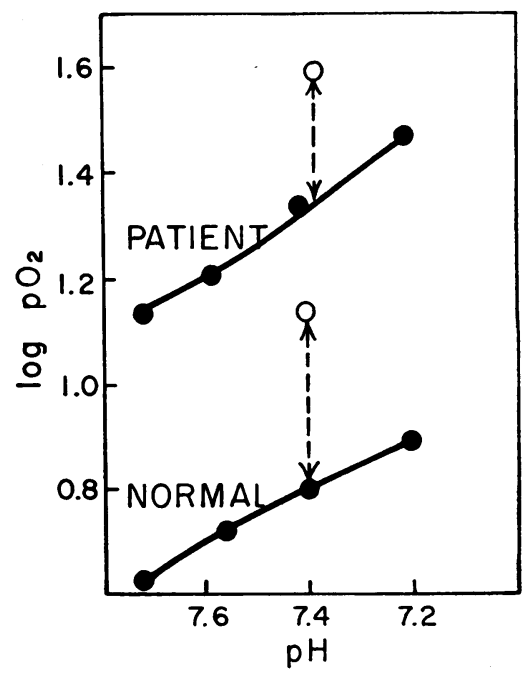

Fig. 3. EFFect of PH AND temperature on halfSaturation $\left(\mathrm{HBO}_{2}=\mathrm{HB}\right)$ OF HeMOgLobin (APProxiMATely 6 G PER CENT) IN $0.15 \mathrm{M}$ PHOSPhate bufFer. Solid circles at $28^{\circ} \mathrm{C}$, open circles at $37^{\circ} \mathrm{C}$. 


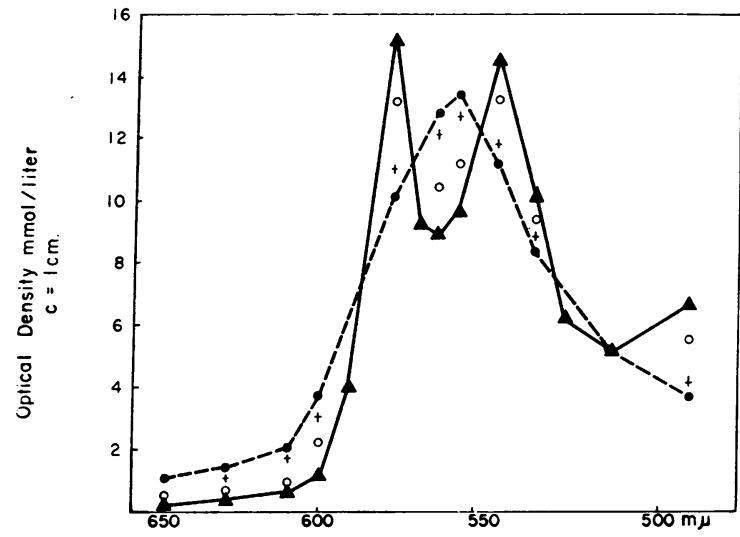

Fig. 4. ABsorption SPECTRA OF THE PATIENT'S HeMOLYZED BLOOD (UNDILUTED IN 0.0087 CM CUVET). $\Delta-\Delta$ after equilibration with $100 \% \mathrm{O}_{2}$ at $20^{\circ} \mathrm{C}$; after equilibration at zero $\mathrm{P}_{\mathbf{O}_{2}} ;++$ native venous blood; $\bigcirc \bigcirc$ native arterial blood.

samples of the patient were examined under anaerobic conditions on six different occasions and failed to reveal the presence of any pigment other than oxyhemoglobin and hemoglobin. Two examples are indicated in Figure 4. The light absorption of arterial blood closely fitted a theoretical curve representing 59 per cent oxyhemoglobin and 41 per cent hemoglobin. Venous blood followed a predicted curve of 18 per cent oxyhemoglobin and 82 per cent hemoglobin. Although these absorption spectra were obtained within 10 minutes after shedding of the blood, the remote possibility remained that a circulating methemoglobin might have been reduced during this time, perhaps due to a delayed reductase activity. Blood was therefore collected with and without $\mathrm{KCN}$ present in the sampling syringe. No spectral differences referable to the formation of cyanmethemoglobin were noted.

The absorption spectra in the ultraviolet spectral region, presented in Figure 5, were obtained from the hemoglobin preparations used in the study of the oxygen equilibria. They failed to show any indication of denaturation. The peak of the Soret band of oxyhemoglobin was at 415 $\mathrm{m} \mu$ and that of the hemoglobin at $425 \mathrm{~m} \mu$. The tryptophan and phenylalanine bands were at the same wave lengths and of similar amplitude as the bands observed in the normal controls.

Absorption spectra of the ferri-hemoglobins. The methemoglobin produced by in vitro oxidation of the hemolysates from the patient and his mother exhibited identical abnormalities (Figure $6)$. The greater optical density of the patient's methemoglobin ( $\mathrm{pH}$ 6.5) in the green spectral region is not caused by incomplete oxidation of some hemes, because it extends into the 530 to
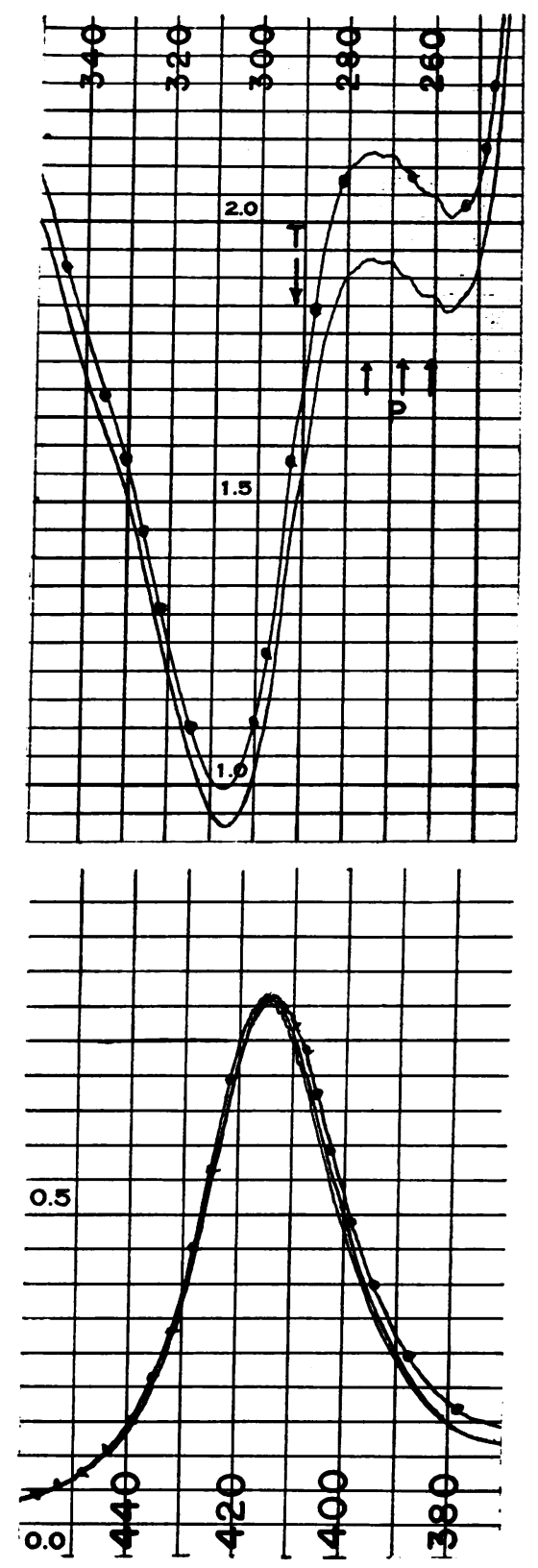

Fig. 5. Ultraviolet absorption SPECtra of hemoGLOBIN SOLUTIONS. The curve marked by solid circles is that of the patient. Lower: Soret band of $\mathrm{HbO}_{2}$; upper: tryptophan $(\mathrm{T})$ and phenylalanine $(\mathrm{P})$ bands of $\mathrm{Hb}$. (Wave lengths in millimicrons.) 


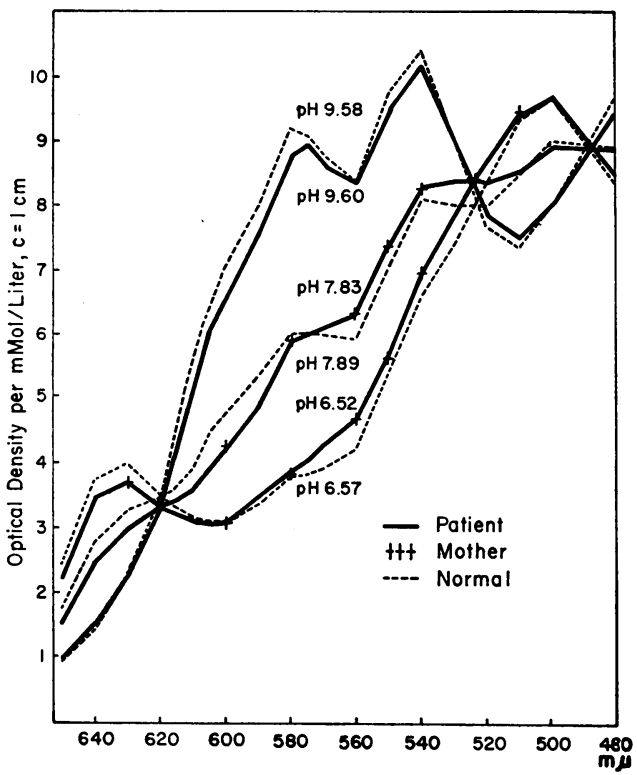

Fig. 6. Absorption SPECtRA of Methemoglobin. $\mathrm{pH}$ as indicated; phosphate or borate buffer of 0.1 ionic strength.

$510 \mathrm{~m} \mu$ region where both oxyhemoglobin and hemoglobin have lower light absorptions than has methemoglobin. Furthermore, mathematical analysis of the curves at several $\mathrm{pH}$ 's indicates that if the curves represent mixtures, the light absorption of both components must be highly $\mathrm{pH}$-dependent, which is not the case in ferro-hemoglobins. The Soret peak of the patient's methemoglobin was at $408 \mathrm{~m} \mu$ as compared with $406 \mathrm{~m} \mu$ in methemoglobin A. The described spectral abnormalities were readily reproducible. They did not change on addition of excess ferricyanide or after standing several days. They are considered to be a manifestation of abnormal molecular structure of the abnormal pigment. To allow absolute comparisons, all absorption spectra are presented as millimolar densities which refer to the total pigment concentration and not necessarily to the concentration of the abnormal pigment.

The dissociation of methemoglobin $\left(\mathrm{Fe}^{+++} \mathrm{OH}_{2}\right)$ into the alkaline form $\left(\mathrm{Fe}^{+++} \mathrm{OH}\right)$ is demonstrated in Figure 7. The difference in the $\mathrm{pK}$ between normai and the patient's pigment is of doubtful significance. The oxidized pigment of the patient reacted quantitatively with potassium cyanide, and the resultant cyanmethemoglobin exhibited essentially normal absorption spectra.

Electrophoretic findings. Starch block electro- phoresis of the oxyhemoglobin, carboxyhemoglobin and cyanmethemoglobin preparations did not reveal significant differences in the migration of the patient's pigment in comparison with hemoglobin $\mathrm{A}$, except for a very light $\mathrm{A}_{2}$ component in the patient. On starch block electrophoresis of the methemoglobin form at $\mathrm{pH}$ 8.6, patterns were obtained which were identical in the patient and his mother and which could easily be distinguished from methemoglobin A (Figure 8). The bulk of the patient's pigment migrated more slowly than methemoglobin A, but it is difficult to decide whether the spot of the latter was entirely vacated. Eluates from this portion gave absorption spectra identical with the main band, and both were indistinguishable from the absorption spectrum of the pigment before electrophoresis. At $\mathrm{pH} 7.05$ and at 6.5 the patient's methemoglobin migrated more slowly toward the cathode than did methemoglobin A. The dissociation of the $\mathrm{Fe}^{+++} \mathrm{OH}_{2}$ was not significantly different in the patient's methemoglobin (Figure 7) and the anomalous change in the net charges at alkaline $\mathrm{pH}$ therefore reflects differences in the $\mathrm{pK}$ of other groups.

\section{DISCUSSION}

The lack of hypoxic manifestations in the intensely cyanotic patient is explained by the shift of the entire oxyhemoglobin dissociation curve (Figure 1). Assuming a normal tissue $\mathrm{P}_{\mathrm{O}_{2}}$ of $35 \mathrm{~mm} \mathrm{Hg}$ and disregarding the Bohr effect, normal blood can dissociate from 95 per cent arterial saturation to 60 per cent oxyhemoglobin in the

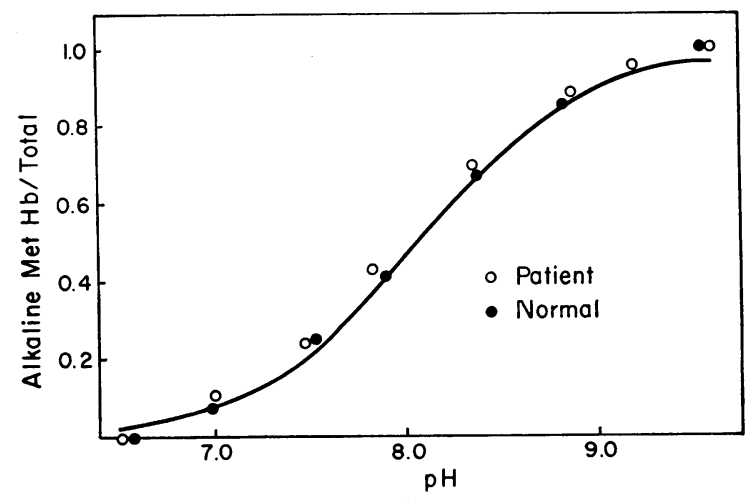

Fig. 7. Dissociation of methemoglobin. The solid line describes the theoretical dissociation with a $\mathrm{pK}$ of 8.06. Circles are the observed values corrected to ionic strength of 0.10 . 
tissue capillaries. The patient's arterial blood was only 60 per cent saturated, but it dissociated to 25 per cent oxyhemoglobin at the same tissue tension. It thus delivers. like normal blood, 35 per cent of its oxygen capacity at peripheral oxygen tensions of $35 \mathrm{~mm} \mathrm{Hg}$.

The observed low oxygen affinity of the hemoglobin in buffered solutions leaves little doubt that the abnormal dissociation curve of the blood was caused by the properties of the hemoglobin and not by an abnormal environment within the red cell. Abnormal dissociation curves of the blood from subjects suffering from hemoglobin $\mathrm{S}$ disease have been reported $(12,13)$. The inherent oxygen affinity of hemoglobin $\mathrm{S}$ after dialysis was found to be normal, and the abnormal oxygen affinity of the blood has been attributed to dialyzable constituents within the red cell. The buffered and dialyzed hemoglobin solutions from our patients showed lowered oxygen affinities proportional to those found in their whole blood.

Numerous spectroscopic examinations of the native blood as well as of the hemoglobin solutions failed to detect any pigment with spectral characteristics other than those of oxyhemoglobin and hemoglobin. The patient's arterial blood contained 60 per cent oxyhemoglobin. If a significant portion of the remaining 40 per cent were different from reduced hemoglobin, it should have been detectable in spite of the limited accuracy of spectrophotometric analysis of systems with more than two components.

A shift in the peak of the Soret band to shorter wave length is, according to Jope (14), one of the most sensitive criteria of denaturation of a hemoglobin. The Soret peak of the oxyhemoglobin from the patient was precisely at $415 \mathrm{~m} \mu$ and that of his hemoglobin at $425 \mathrm{~m} \mu$. Denaturation can not be incriminated, therefore, as the cause of the abnormal oxygen affinity. Although it can be influenced by major changes in the protein carrier, the absorption spectrum in the spectral region between 700 and $350 \mathrm{~m} \mu$ is primarily a reflection of the configuration of the hemes. The quantitatively normal absorption spectra of both the oxyhemoglobin and the hemoglobin form of the abnormal pigment in this spectral region lends no support to any abnormality in the heme groups. These findings in conjunction with the anomalous electrophoretic mobility implicate the amino acid

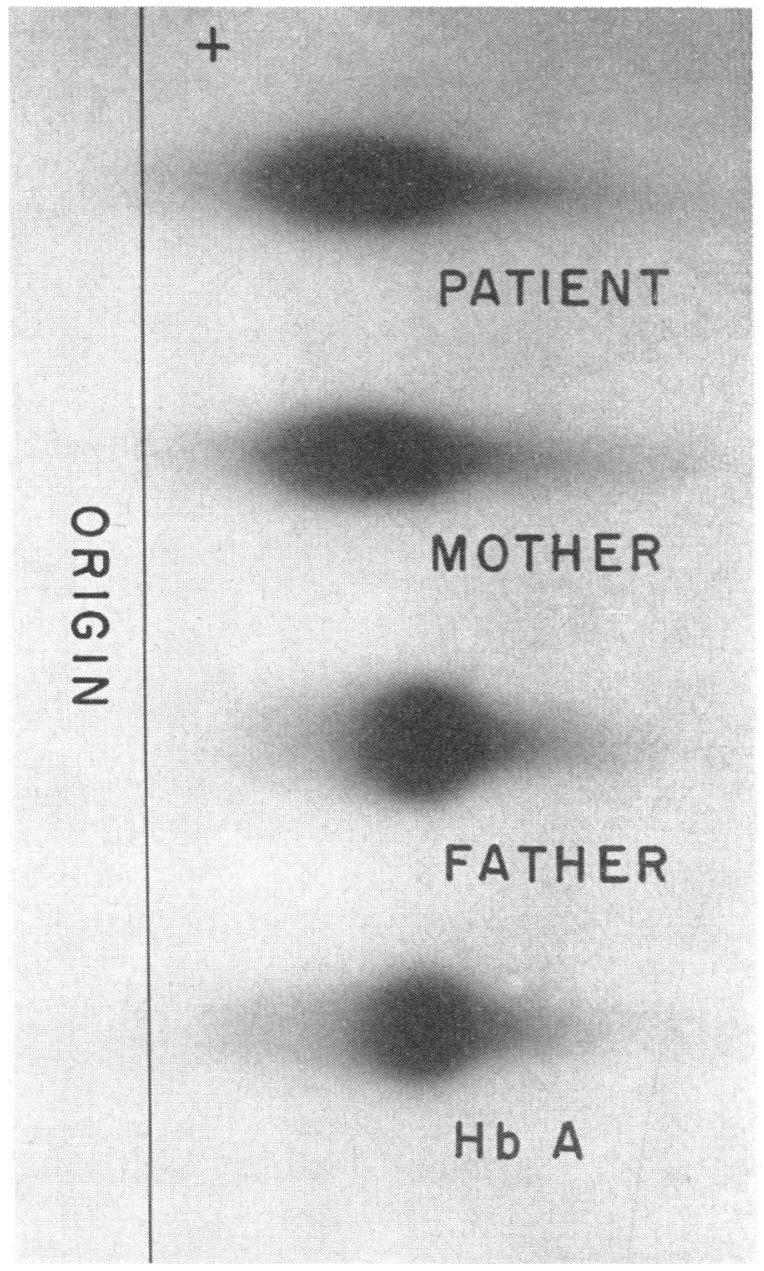

Fig. 8. Starch block electrophoresis of MEtheMOGLOBIN. Veronal buffer; 0.05 ionic strength, $\mathrm{pH}$ 8.6, $250 \mathrm{v}, 40 \mathrm{ma}, 16$ hours.

chains as the probable site of the abnormality. The relatively slight alteration in electrophoretic mobility in no way conflicts with the large abnormality of the oxygen affinity. The former depends upon net electrical charges in the protein molecule and does not necessarily reflect structural abnormalities which alter oxygen affinity.

The shape of the oxyhemoglobin dissociation curve deserves some comment. In the semilogarithmic presentation (Figure 2) factors like $\mathrm{pH}$ and temperature, which affect oxygen affinity. merely displace the curve along the abscissa but they do not alter its shape. The steepness of the normal curve is attributed to the heme-heme interactions in the sense that the oxygenation of one or more of the hemes facilitates the oxygenation 


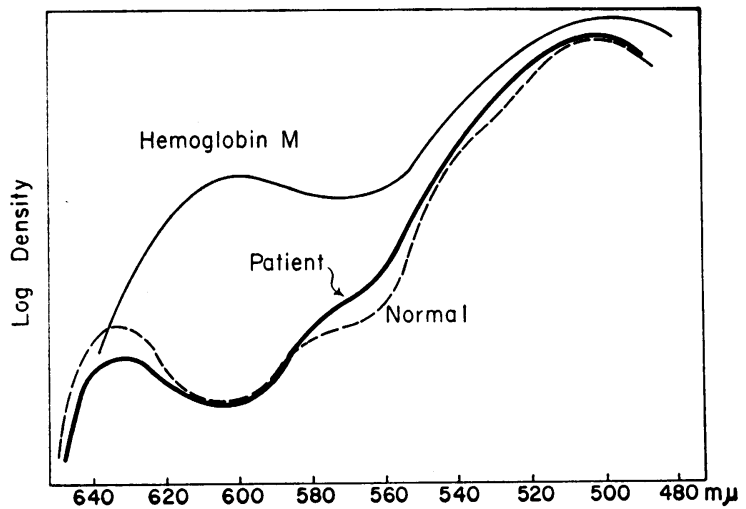

Fig. 9. Comparison of the spectral abNormalities OF THE PATIENT'S OXIDIZED HEMOGLOBIN WITH METHEMOGLOBIN M (21) AT PH 6.5.

of the remaining hemes in the same molecule (1, $2)$. It is convenient to assign a numerical value to the intensity of this interaction by calculating the $n$ value in the logarithmic form of Hill's equation, although it is realized that the equation no longer has precise physical meaning as originally thought. An $n$ value of 1 is found in pigments without interactions, for instance in myoglobin which contains only 1 heme per molecule. The abnormal hemoglobin exhibited an $n$ value of 1.1 versus 2.6 in the normal control. One is tempted to interpret this finding as the absence of hemeheme interactions in the abnormal hemoglobin; however, uncertainties arise from the lack of unequivocal electrophoretic isolation of the abnormal hemoglobin. The hemolysate very likely contained unknown amounts of a normally reactive hemoglobin. It is theoretically possible that the flat oxyhemoglobin dissociation curve in Figure 2 is the resultant of the curve of the normal fraction plus an equally steep curve of the abnormal fraction which lies considerably to the right of the normal curve.

Riggs (15) has reported a large though not complete blocking of the heme interactions resulting from blocking of the sulfhydryl groups of normal hemoglobin by means of $p$-chloromercuribenzoate. The $n$ value dropped from 2.9 to 1.4 , and the effect could be reversed largely by glutathione. Addition of glutathione has not changed the oxygen equilibria of the patient's hemoglobin, but this negative result permits no conclusion regarding an intrinsic abnormality of the sulfhydryl groups.
The described hemoglobin shows some similarities to hemoglobin $M$, viz.. it causes cyanosis, its oxidized form exhibits spectral abnormalities, and electrophoretic abnormalities can best be demonstrated in its met form. In some cases of hemoglobin $\mathrm{M}$, including the original case of Hörlein and Weber (16), up to 30 per cent methemoglobin of abnormal spectral characteristics was present in the native blood and accounted for the cyanosis $(17,18)$. In the case reported by Kiese, Kurz and Schneider (19), enzymatic reduction of this methemoglobin fraction yielded a hemoglobin with normal oxygen affinity. If these findings apply generally to hemoglobin $M$, the primary defect in its oxygen transport function would be its tendency to become oxidized due to structural abnormalities in the molecule, a mechanism quite different from the truly diminished oxygen affinity in our abnormal hemoglobin. In other cases classified as hemoglobin M (20, 21 ), including a large number reported in Japan (22), no oxidized pigment could be detected in the blood. Only in vitro oxidation produced a fraction of the methemoglobin with abnormal spectral characteristics similar to those found in the first-mentioned group. No oxygen equilibria have been reported in these cases, but it is assumed that the pigment present in these cyanotic patients was unable to combine reversibly with oxygen. A comparison. of the spectral abnormalities of the met form of hemoglobin $\mathrm{M}$ and of the pigment reported here is given in Figure 9. Since the absolute absorption of both abnormal pigments is unknown, the absorption spectra are presented as the logarithm of optical densities in order to make the shape of the curve independent of concentration. The rather different spectral abnormalities very likely reflect different molecular structure, which is also manifested by their differences in reactivity toward oxygen.

In spite of these significant differences, the various types of hemoglobin $\mathrm{M}$ and the pigment reported here may belong to the same functional group of abnormal hemoglobins, namely those with aberrations in amino acid groups which are crucial in the interaction between globin and the oxygen-combining centers. Several hypothetical explanations of the normal interactions have been advanced, especially in connection with the Bohr effect and the heme-heme interactions (2). The 
chemical rature of the groups involved, even that of the heme-linked acid groups, is still an open question (1). It would be premature therefore to speculate on the globin anomalies of the described hemoglobin. It is to be expected that future elucidation of amino acid anomalies in this now emerging group of hemoglobins with altered oxygen affinity may shed some light on the nature of the normal heme-globin interactions.

\section{SUMMARY}

A familial human hemoglobin variant is described which caused markedly diminished oxygen saturation of the blood in the presence of normal arterial oxygen tensions. The shift of the entire oxyhemoglobin dissociation curve was due to an abnormally low oxygen affinity of the hemoglobin. The oxygen equilibria of the pigment in buffer solutions revealed a Bohr effect of normal magnitude but probably no heme-heme interactions. The absorption spectra of its oxy and reduced form in the visible and ultraviolet spectral region were those of normal hemoglobin. The alkaline and acid methemoglobin showed spectral abnormalities. On starch block electrophoresis, the methemoglobin form of the pigment migrated more slowly than methemoglobin A. The lowered oxygen affinity is attributed to molecular aberrations in the globin which interfere with normal heme-globin interactions.

\section{REFERENCES}

1. Edsall, J. T. Current concept of structure of hemoglobin in Conference on Hemoglobin. Washington, D. C., National Academy of Sciences, National Research Publication no. 557, 1958, p. 1.

2. Wyman, J., and Allen, D. W. The problem of hemeinteractions in hemoglobin and the basis of the Bohr effect. J. Polym. Sci. 1951, 7, 499.

3. Benesch, R., Ranney, H. M., and Benesch, R. E. Some properties of hemoglobin H. Fed. Proc. 1961, 20, 70.

4. Beaven, G. H., and Gratzer, W. B. A critical review of human haemoglobin variants. II. Individual haemoglobins. J. clin. Path. 1959, 12, 101.

5. Severinghaus, J. W., and Bradley, A. F. Electrodes for blood $\mathrm{pO}_{2}$ and $\mathrm{pCO}_{2}$ determination. J. appl. Physiol. 1958, 13, 515.

6. Fister, H. J. Manual of Standardized Procedures for Spectrophotometric Chemistry. New York, Standard Scientific Supply Corp., 1950.
7. Austin, J. H., and Drabkin, D. L. Spectrophotometric studies: III. Methemoglobin. J. biol. Chem. 1935, $112,67$.

8. Drabkin, D. L. Aspects of oxygenation and oxidation functions in Haemoglobin, F. J. W. Roughton and J. C. Kendrew, Eds. London, Butterworth, 1949, p. 35.

9. Kunkel, H. G. Zone electrophoresis in Methods in Biochemical Analysis, D. Glick, Ed. New York, Interscience Publishers, 1954, vol. 1, p. 141.

10. Ferry, R. M., and Green, A. A. Studies in the chemistry of hemoglobin. III. The equilibrium between oxygen and hemoglobin and its relation to changing hydrogen ion activity. J. biol. Chem. 1929, 81. 175.

11. McCarthy, E. F. The oxygen affinity of human maternal and foetal haemoglobin. J. Physiol. (Lond.) 1943, 102, 55.

12. Becklake, M. R., Griffiths, S. B., McGregor, M., Goldman, H. I., and Schreve, J. P. Oxygen dissociation curves in sickle cell anemia and in subjects with the sickle cell trait. J. clin. Invest. 1955 , 34, 751.

13. Rodman, T., Close, H. P., Cathcart, R., and Purcell, M. K. The oxyhemoglobin dissociation curve in common hemoglobinopathies. Amer. J. Med. 1959, 27,558 .

14. Jope, E. M. The ultarviolet spectral absorption of haemoglobins inside and outside the red blood cell in Haemoglobin, F. J. W. Roughton and J. C. Kendrew, Eds. London, Butterworth, 1949, p. 205.

15. Riggs, A. F. Sulfhydryl groups and the interaction between the hemes in hemoglobin. J. gen. Physiol. 1953, 36, 1.

16. Hörlein, H., and Weber, G. Über chronische familiäre Methämoglobinämie und eine neue Modifikation des Methämoglobins. Dtsch. med. Wschr. 1948, 73, 476.

17. Heck, W., and Wolf, H. Angeborener Herzfehler mit Cyanose durch pathologischen Blutfarbstoff (Hämoglobin M). Ann. paediat. (Basel) 1958, $190,135$.

18. Pisciotta, A. V., Ebbe, S. N., and Hinz, J. E. Clinical and laboratory features of two variants of methemoglobin $\mathrm{M}$ disease. J. Lab. clin. Med. 1958, 54, 73.

19. Kiese, M., Kurz, H., and Schneider, C. Chronische Hämiglobinämie durch pathologischen Blutfarbstoff. Klin. Wschr. 1956, 34, 957.

20. Gerald, P. S. The electrophoretic and spectroscopic characterization of Hgb M. Blood 1958, 13, 936.

21. Gerald, P. S., and George, P. Second spectroscopically abnormal methemoglobin associated with hereditary cyanosis. Science 1959, 129, 393.

22. Shibata, S., Tamura, A., Inchi, I., and Takahashi, H. Hemoglobin $\mathrm{M}_{1}$ : Demonstration of a new abnormal hemoglobin in hereditary nigremia. Acta haemat. jap. 1960, 23, 96. 